\title{
Pharmacological Suppression of Endogenous Glucocorticoid Synthesis Attenuated Blood Pressure and Heart Rate Response to Acute Restraint in Wistar Rats
}

\author{
Michal BENCZE ${ }^{1}$, Anna VAVŘíNOVÁ ${ }^{1}$, Josef ZICHA ${ }^{1}$, Michal BEHULIAK ${ }^{1}$ \\ ${ }^{1}$ Laboratory of Experimental Hypertension, Institute of Physiology, Czech Academy of Sciences, \\ Prague, Czech Republic
}

Received January 10, 2020

Accepted March 5, 2020

Epub Ahead of Print May 29, 2020

\section{Summary}

Glucocorticoids (GCS) are known to modulate cardiovascular response during stress conditions. The present study was aimed to test the hypothesis that permissive and/or stimulating effect of GCs is essential for the maintenance of peripheral vascular resistance and for the adequate response of cardiovascular system to stressor exposure. The effects of acute pharmacological adrenalectomy (PhADX) on humoral and cardiovascular parameters were studied in adult Wistar rats under the basal conditions and during the acute restraint stress. Acute PhADX was performed by the administration of metyrapone and aminoglutethimide (100 mg/kg s.c. of each drug) resulting in a suppression of endogenous glucocorticoid synthesis. Blood pressure (BP), heart rate (HR) and core body temperature were measured using radiotelemetry. BP responses to administration of vasoactive agents were determined in pentobarbital-anesthetized animals. PhADX considerably attenuated stress-induced increase of $\mathrm{BP}, \mathrm{HR}$ and core body temperature. PhADX did not abolish BP and HR lowering effects of ganglionic blocker pentolinium indicating preserved sympathetic function in PhADX rats. BP response to exogenous norepinephrine administration was attenuated in PhADX rats, suggesting reduced sensitivity of cardiovascular system. Suppression of corticosterone synthesis by PhADX increased basal plasma levels of $\mathrm{ACTH}$, aldosterone and plasma renin activity in unstressed animals but there was no further increase of these hormones following stressor exposure. In conclusion, PhADX attenuated stress-induced rise of blood pressure, heart rate and core body temperature indicating an important permissive and/or stimulating role of glucocorticoids in the maintenance of the adequate response of cardiovascular system and thermoregulation to several stimuli including acute exposure to stressor.

\section{Key words}

Stress - Adrenalectomy - Metyrapone - Aminoglutethimide • Corticosterone $\bullet$ Blood pressure $\bullet$ Heart rate

\section{Corresponding author}

M. Behuliak, Laboratory of Experimental Hypertension, Institute of Physiology of the Czech Academy of Sciences, Videnska 1083, CZ-142 20 Prague 4, Czech Republic. E-mail: michal.behuliak@fgu.cas.cz

\section{Introduction}

The most common stress-induced allostatic responses (adaptive mechanisms aiming to maintain or reinstate homeostasis) involve an activation of sympathetic nervous system, sympathetic adrenomedullary system and hypothalamic-pituitaryadrenal axis (McEwen 1998, Goldstein 2010, Koolhaas et al. 2011). Cardiovascular response to acute exposure to stressor, involving the elevation of blood pressure (BP), heart rate (HR) and cardiac output, results mainly from the increased sympathetic nerve activity in vasculature and heart as well as from the enhanced release of catecholamines from adrenal medulla (Dos Reis et al. 2014). Stress-induced activation of HPA axis not only promotes the mobilization of stored energy but also modulates cardiovascular stress response (Sapolsky et al. 2000). Fritz and Levine (1951) reported that in situ 
contractile sensitivity of mesenteric arteries to norepinephrine (NE) was greatly reduced in adrenalectomized rats compared to controls and can be restored by topical application of an adrenal cortical extract. It is widely accepted that glucocorticoids (GCs) help to mediate permissively the cardiovascular stress response through the potentiation of catecholamine action in both vascular and cardiac tissue (Ullian 1999, Sapolsky et al. 2000). On the other hand, adrenalectomy stimulates several aspects of sympatho-neural function, including stress-induced NE release and catecholamine biosynthesis, which has been interpreted by some authors as the evidence for suppressive GCs action preventing overshooting of stress-induced cardiovascular response (Brown and Fisher 1986, Kvetňanský et al. 1993).

Although the stress-induced changes in humoral and cardiovascular responses are well known, detailed description of these parameters during stress response in the absence of GCs is missing. Pharmacological adrenalectomy (PhADX) which causes a suppression of glucocorticoid synthesis was proposed to be a valid alternative to surgical adrenalectomy (Plotsky and Sawchenko 1987). It represents a tool for the study of cardiovascular and humoral responses to acute stress in the absence of GCs but with intact adrenal medulla and without additional stress caused by the surgery. Furthermore, chronically implanted radiotelemetric probes for monitoring blood pressure, heart rate and body temperature also offer the advantage of removing the undesirable stress (McDougall et al. 2000).

The present study was aimed to test the hypothesis that permissive and/or stimulating effect of GCs is essential for the maintenance of peripheral vascular resistance and for the adequate response of cardiovascular system to stressor exposure. Therefore, we evaluated the effects of acute pharmacological adrenalectomy on cardiovascular parameters, core body temperature and plasma levels of selected hormones (corticosterone, ACTH, aldosterone, renin) in unstressed rats and under the conditions of acute restraint stress.

\section{Methods}

\section{Animals}

All experiments were performed in male Wistar rats aged 20-22 weeks obtained from the breeding colony of the Institute of Physiology, Czech Academy of Sciences (Prague). Animals were kept under standard laboratory conditions (temperature $23 \pm 1^{\circ} \mathrm{C}, 12$-h light- dark cycle, Altromin pellet diet, tap water ad libitum). There were three series of rats - one for radiotelemetry measurements (Experiment 1), the second for collection of blood samples (Experiment 2) and the last series for determination of $\mathrm{BP}$ response to $\mathrm{NE}$ administration (Experiment 3). All experimental procedures were approved by the Ethical Committee of the Institute of Physiology, Czech Academy of Sciences and conform to the European Convention on Animal Protection and Guidelines on Research Animal Use.

\section{Pharmacological adrenalectomy}

Pharmacological suppression of endogenous glucocorticoid synthesis was performed by subcutaneous application of metyrapone and aminoglutethimide (100 $\mathrm{mg} / \mathrm{kg}$ of each drug solved in DMSO, Santa Cruz Biotechnology, USA). Metyrapone is inhibitor of 11- $\beta$-hydroxylase and aminoglutethimide blocks several cytochrome P-450 mediated steroid hydroxylation steps, including the synthesis of pregnenolone from cholesterol (Santen and Misbin 1981, Plotsky and Sawchenko 1987). Control (CTRL) rats were injected with DMSO. Drug administration was performed between 09:30 and 10:30 $\mathrm{AM}$, i.e. two hours before the stress exposure.

\section{Acute restraint stress protocol}

Rats were subjected to single restraint stress for $120 \mathrm{~min}$ or $10 \mathrm{~min}$ (Experiment 1 or 2, respectively). Animals were placed horizontally into the transparent cylindrical plastic restrainers equipped with ventilation holes and the length of cylinder was adjusted according to animal size (Vavř́nová et al. 2019).

\section{Radiotelemetry measurements (Experiment 1)}

Rats were implanted with telemetry transmitters (model HD-S10, Data Sciences International, USA) under the anesthesia with isoflurane ( $5 \%$ for induction and 2-3\% for maintenance; Forane, AbbVie, USA) as previously described (Behuliak et al. 2018, Vavř́nová et al. 2019). Briefly, a midline abdominal incision was made and the catheter of the transmitter was inserted into the abdominal aorta. The transmitter was secured in the abdominal cavity. Rats were left to recover from surgery for 10 days before the onset of the experimental protocol. Transmitted data were recorded and analyzed using the Dataquest A.R.T. System (Data Sciences International, USA). BP, HR and core body temperature were evaluated in 5-min intervals (recorded four times per hour) in freely-moving or restrained rats. Power spectral analysis 
of systolic blood pressure variability (SBPV) was used to determine the components of SBPV - very low-frequency (VLF SBPV; 0.02-0.2 Hz), low-frequency (LF SBPV; 0.2-0.75 Hz) and high-frequency (HF SBPV; 0.75-4 Hz). LF SBPV and HF SBPV represent markers of sympathetic vascular and cardiac activity, respectively (Stauss 2007, Yoshimoto et al. 2011). Baroreflex function was determined from telemetric recordings by the spontaneous sequences method (Bertinieri et al. 1985) using Hemolab software ver. 21.0 (Vavř́nová et al. 2019).

After 10-day recovery from the surgery, acute cardiovascular response to subcutaneous injection of metyrapone and aminoglutethimide $(100 \mathrm{mg} / \mathrm{kg}$ of each drug; PhADX; $n=6$ ) or solvent DMSO (CTRL; $n=5)$ in freely-moving animals. The animals were left to rest for three days until restoration of cardiovascular parameters back to basal values. Thereafter, the second administration of a combination of both inhibitors or DMSO was performed and rats were subjected to restraint stress protocol (see above) $120 \mathrm{~min}$ after the injection of inhibitors.

Blood sampling and biochemical measurement (Experiment 2)

Samples of blood were collected under the unstressed conditions (basal) and $10 \mathrm{~min}$ after the onset of restraint stress in separate CTRL and PhADX groups of animals ( $n=6$ in each group). The rats were rapidly anesthetized with isoflurane, which does not influence basal and stress-induced corticosterone levels ( $\mathrm{Wu}$ et al. 2015), and blood was collected from thoracic aorta into the EDTA-coated collection tubes (S-Monovette ${ }^{\circledR}$ K3E tubes, SARSTEDT, Germany). Plasma concentrations of catecholamines (norepinephrine and epinephrine) were measured using 2-CAT Research ELISA (LDN, Germany). Plasma corticosterone, aldosterone and ACTH levels were measured using Corticosterone rat/mouse ELISA (LDN), Aldosterone ELISA (LDN) and ACTH ELISA respectively (MD Bioproducts, Switzerland). Plasma renin activity was determined by ELISA (Crystal Chem, USA) based on the measurement of the amount of angiotensin I generated over a specific period $(2 \mathrm{~h})$. The absorbance at $450 \mathrm{~nm}$ was read on microplate reader Tecan Infinite M200 (Tecan Group Ltd., Switzerland).

$B P$ response to administration of the graded doses of norepinephrine (Experiment 3)

CTRL and PhADX rats $(\mathrm{n}=5$ and 6 rats, respectively) were anesthetized by pentobarbital $120 \mathrm{~min}$ after the administration of inhibitors. Pentobarbital anesthesia $(60 \mathrm{mg} / \mathrm{kg})$ was selected because its interference with vasoactive systems (sympathetic nervous system and renin-angiotensin system) is smaller as compared to other anesthetics (Bencze et al. 2013). Polyethylene catheters were inserted into the left carotid artery (PE50 for BP measurements) and jugular vein (PE10 for infusion of drugs) and BP and HR were directly measured immediately after the surgery in rats using PowerLab system (ADInstruments, Australia). After the stabilization period, rats were subjected to the intravenous ganglionic blockade by pentolinium $(5 \mathrm{mg} / \mathrm{kg})$ to eliminate the endogenous sympathetic vasoconstriction. Thereafter, norepinephrine was administered intravenously in increasing noncumulative doses of 0.001-10 $\mu \mathrm{g} / \mathrm{kg}$ (Behuliak et al. 2013).

\section{Statistics}

The data are expressed as means \pm SEM. For the comparison of time courses of telemetrically measured $\mathrm{BP}, \mathrm{HR}$, body temperature and systolic blood pressure variability between control and $\mathrm{PhADX}$ rats, we used two-way repeated measures ANOVA with the main effect of Treatment (CTRL vs. PhADX rats) and Time (withinanimal repeated factor) separately for freely-moving and acutely restrained rats. Follow-up comparisons of the means comprising main effects or simple effects of significant interactions were conducted using Bonferroni post hoc test. Plasma levels of hormones were analyzed by two-way ANOVA with the main effect of Treatment (CTRL vs. PhADX rats) and Stress (basal vs. stress) followed by Bonferroni post hoc test. Sigmoidal fourparametric logistic model was used for fitting of BP response to exogenous NE using SigmaPlot 13.0 (Systat Software, USA). The effect of PhADX on half-maximal effective dose (ED50) of fitted curves was analyzed by Student's $t$-test. The differences were considered to be significant at $\mathrm{p}<0.05$.

\section{Results}

\section{Cardiovascular parameters after acute PhADX}

The subcutaneous injection of DMSO to CTRL rats caused stress reaction - transient increase of mean arterial pressure, HR and core body temperature - which faded away within 60-90 min in CTRL animals (Fig. 1A, C, E). MAP was similar in CTRL and PhADX groups (Fig. 1A), whereas HR remained increased in freely 

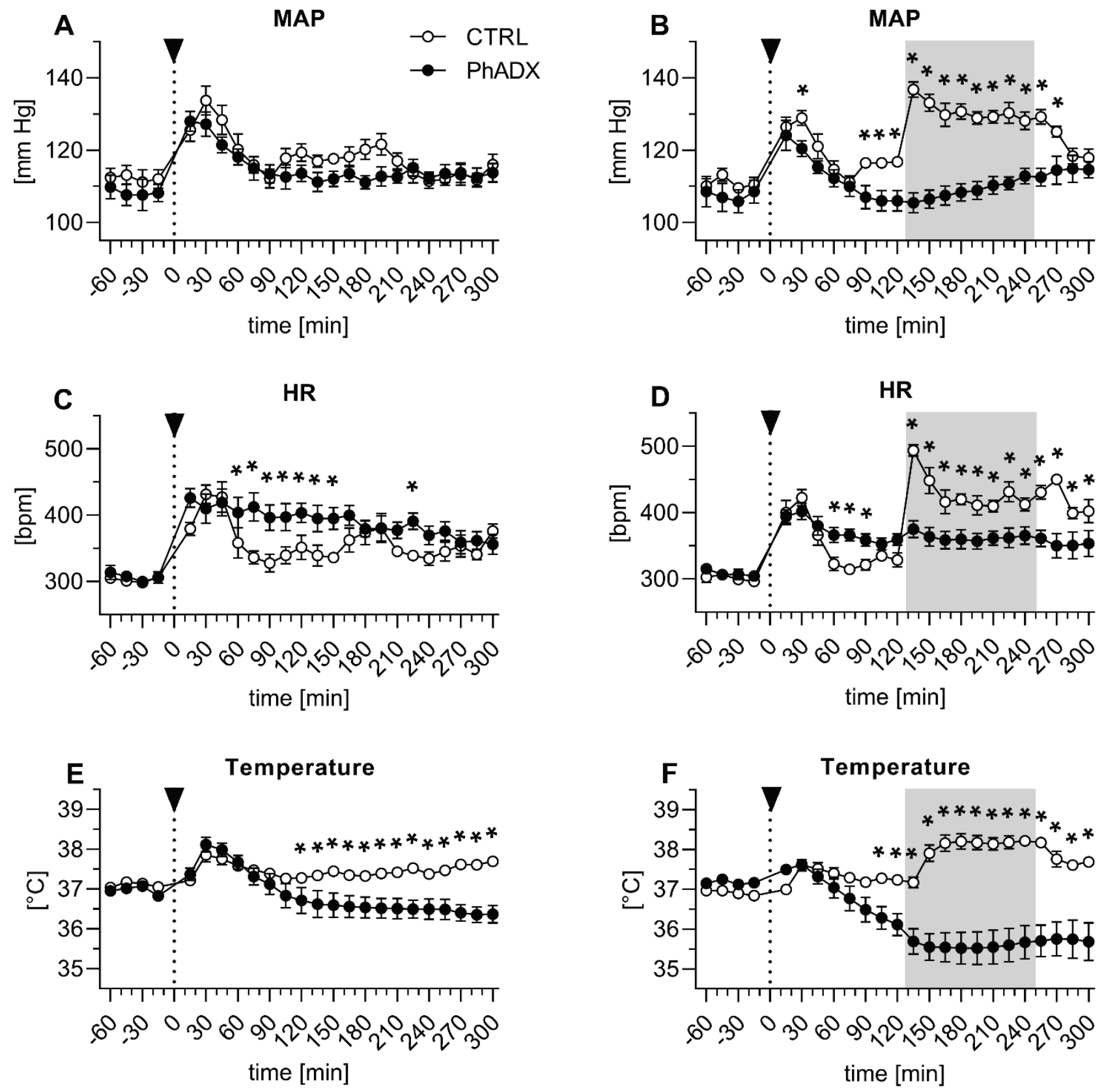

Fig. 1. Time course of mean arterial pressure (MAP), heart rate (HR) and core body temperature in control (CTRL) and pharmacologically adrenalectomized (PhADX) freely-moving $(\mathbf{A}, \mathbf{C}, \mathbf{E})$ or acutely restrained rats (B, D, F). Arrowhead indicates the time of the drug administration. Gray background represents the period of restraint stress. Each point represents mean \pm SEM calculated from values averaged across a 5-min period ( $n=5-6$ rats for each group). Results of two-way repeated measures ANOVA analysis of data are shown in Table 1. The pairwise simple effects of significant interactions were tested by Bonferroni post hoc test: * $p<0.05$ CTRL vs. PhADX group.

moving PhADX animals until 150 min after drugs administration (Fig. 1C). PhADX also elicited a decrease of core body temperature, which became significant 120 min after the injection of inhibitors compared to CTRL group (Fig. 1E). Power spectral analysis of SBPV showed no change in total SBPV, VLF SBPV, LF SBPV (Fig. 2A, C, E), but there was an increase in HF SBPV (representing cardiac sympathetic activity) in PhADX animals (Fig. 2G). In Tables 1 and 2 are results of two-way repeated measures ANOVA analysis of data shown in Figures 1 and 2. Total count of spontaneous baroreflex sequences (sBRS) was substantially decreased in PhADX group (CTRL 299 \pm 95 , PhADX 66 $\pm 26, \mathrm{p}<0.05$ ), but sBRS slope was not affected by the PhADX treatment (CTRL $1.6 \pm 0.1 \mathrm{~ms} / \mathrm{mm} \mathrm{Hg}$, PhADX $1.5 \pm 0.2 \mathrm{~ms} / \mathrm{mm} \mathrm{Hg}$ ). 

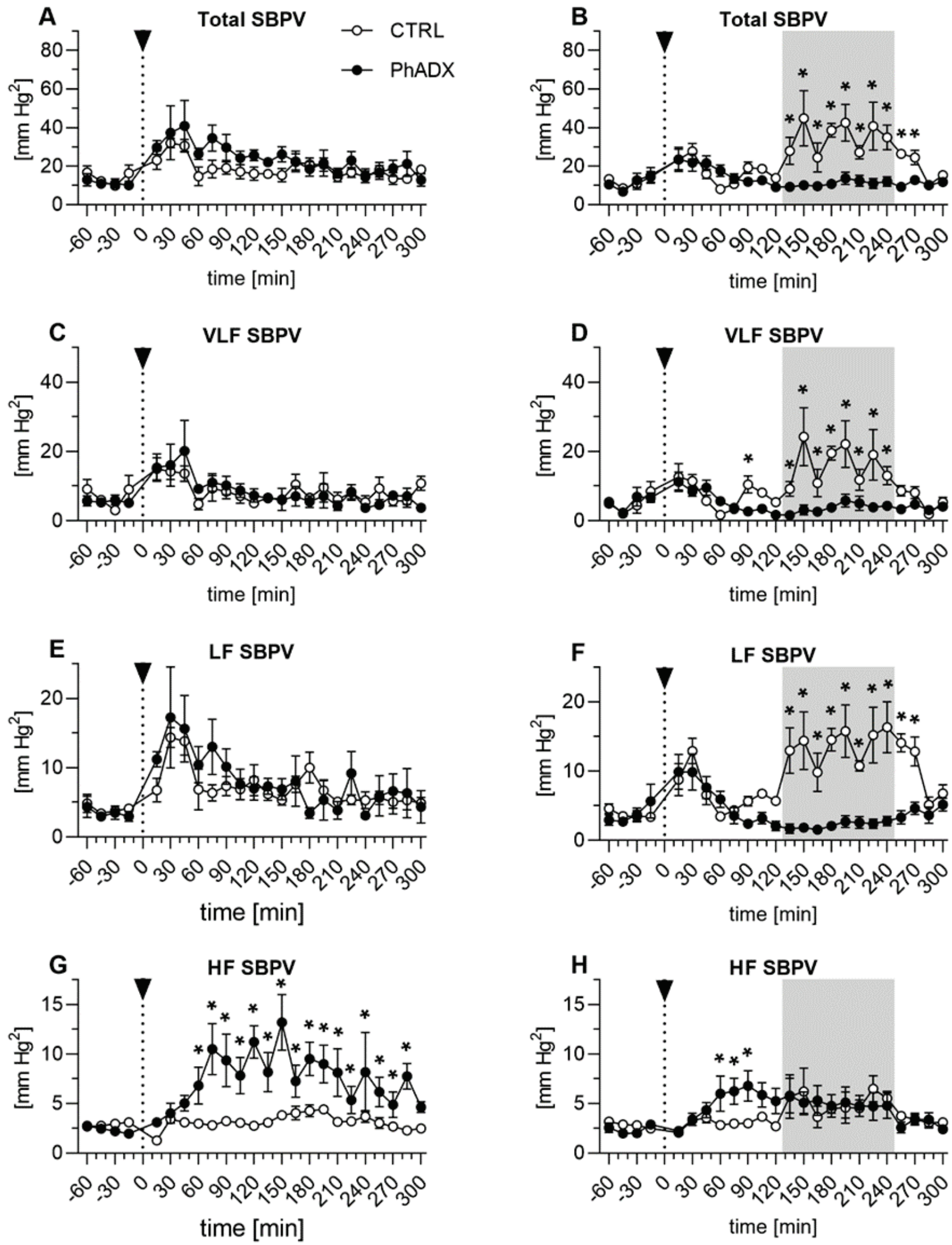

Fig. 2. Time course of total systolic blood pressure variability (total SBPV) and its particular components (very low-frequency, VLF SBPV; low-frequency, LF SBPV; high-frequency, HF SBPV) in control (CTRL) and pharmacologically adrenalectomized (PhADX) freelymoving $(\mathbf{A}, \mathbf{C}, \mathbf{E}, \mathbf{G})$ or acutely restrained rats $(\mathbf{B}, \mathbf{D}, \mathbf{F}, \mathbf{H})$. Arrowhead indicates the time of the drug administration. Gray background represents the period of restraint stress. Each point represents mean \pm SEM calculated from values averaged across a 5-min period ( $n=5-6$ rats for each group). Results of two-way repeated measures ANOVA analysis of data are shown in Table 2 . The pairwise simple effects of significant interactions were tested by Bonferroni post hoc test: * $\mathrm{p}<0.05$ CTRL vs. PhADX group. 
Table 1. Results of two-way repeated measures ANOVA analysis for data shown in Fig. 1. The main effects of Treatment (CTRL vs. PhADX rats), Time (repeated factor) and their Interaction on mean arterial pressure (MAP), heart rate (HR) and temperature were determined.

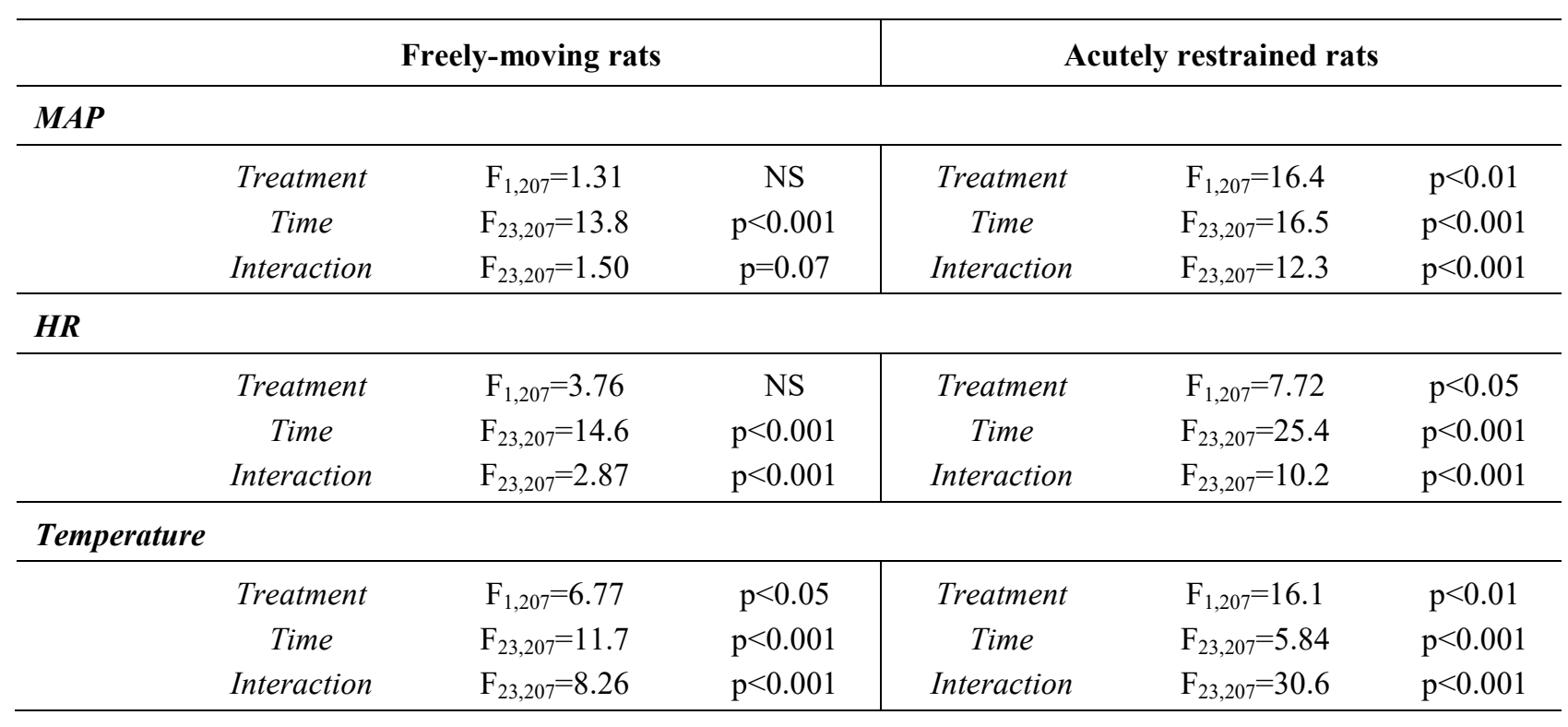

Table 2. Results of two-way repeated measures ANOVA analysis for data shown in Fig. 2. The main effects of Treatment (CTRL vs. PhADX rats), Time (repeated factor) and their Interaction on total systolic blood pressure variability (total SBPV) and its particular components (very low-frequency, VLF SBPV; low-frequency, LF SBPV; high-frequency, HF SBPV) were determined.

\begin{tabular}{|c|c|c|c|c|c|c|}
\hline & \multicolumn{3}{|c|}{ Freely-moving rats } & \multicolumn{3}{|c|}{ Acutely restrained rats } \\
\hline \multicolumn{7}{|l|}{ Total SBPV } \\
\hline & Treatment & $\mathrm{F}_{1,201}=1.54$ & NS & Treatment & $\mathrm{F}_{1,201}=9.33$ & $\mathrm{p}<0.05$ \\
\hline & Time & $\mathrm{F}_{23,201}=4.62$ & $\mathrm{p}<0.001$ & Time & $\mathrm{F}_{23,201}=4.97$ & $\mathrm{p}<0.001$ \\
\hline & Interaction & $\mathrm{F}_{23,201}=1.05$ & NS & Interaction & $\mathrm{F}_{23,201}=5.42$ & $\mathrm{p}<0.001$ \\
\hline \multicolumn{7}{|l|}{$V L F S B P V$} \\
\hline & Treatment & $\mathrm{F}_{1,201}=0.02$ & NS & Treatment & $\mathrm{F}_{1,201}=11.7$ & $\mathrm{p}<0.01$ \\
\hline & Time & $\mathrm{F}_{23,201}=3.15$ & $\mathrm{p}<0.001$ & Time & $\mathrm{F}_{23,201}=4.82$ & $\mathrm{p}<0.001$ \\
\hline & Interaction & $\mathrm{F}_{23,201}=0.72$ & NS & Interaction & $\mathrm{F}_{23,201}=4.44$ & $\mathrm{p}<0.001$ \\
\hline \multicolumn{7}{|l|}{$L F S B P V$} \\
\hline & Treatment & $\mathrm{F}_{1,201}=0.21$ & NS & Treatment & $\mathrm{F}_{1,201}=15.3$ & $\mathrm{p}<0.01$ \\
\hline & Time & $\mathrm{F}_{23,201}=5.13$ & $\mathrm{p}<0.001$ & Time & $\mathrm{F}_{23,201}=5.31$ & $\mathrm{p}<0.001$ \\
\hline & Interaction & $\mathrm{F}_{23,201}=0.93$ & NS & Interaction & $\mathrm{F}_{23,201}=7.08$ & $\mathrm{p}<0.001$ \\
\hline \multicolumn{7}{|l|}{$H F S B P V$} \\
\hline & Treatment & $\mathrm{F}_{1,201}=15.2$ & $\mathrm{p}<0.01$ & Treatment & $\mathrm{F}_{1,201}=0.25$ & NS \\
\hline & Time & $\mathrm{F}_{23,201}=4.39$ & $\mathrm{p}<0.001$ & Time & $\mathrm{F}_{23,201}=3.88$ & $\mathrm{p}<0.001$ \\
\hline & Interaction & $\mathrm{F}_{23,201}=3.06$ & $\mathrm{p}<0.001$ & Interaction & $\mathrm{F}_{23,201}=1.94$ & $\mathrm{p}<0.01$ \\
\hline
\end{tabular}

Cardiovascular response to restraint after acute PhADX

PhADX was performed as in the previous experiment and rats were subjected to restraint stress, which started $120 \mathrm{~min}$ after the administration of inhibitors, and lasted $120 \mathrm{~min}$. In CTRL animals the stress increased cardiovascular parameters (average
$120 \mathrm{~min}$ changes in MAP $+14 \pm 2 \mathrm{~mm} \mathrm{Hg}$, HR $+102 \pm 16$ bpm, $\mathrm{p}<0.01$ both, Fig. $1 \mathrm{~B}, \mathrm{D})$ and core body temperature $\left(+0.8 \pm 0.1^{\circ} \mathrm{C}, \mathrm{p}<0.01\right.$, Fig. $\left.1 \mathrm{~F}\right)$. In contrast, there were no significant stress-induced changes in MAP, HR and temperature in PhADX animals (MAP $+3 \pm 1 \mathrm{~mm} \mathrm{Hg}, \mathrm{HR}+4 \pm 10 \mathrm{bpm}$, temperature $-0.5 \pm 0.1^{\circ} \mathrm{C}$; 
Fig. 1B, D, F). Restraint stress increased total SBPV, VLF SBPV and LF SBPV (representing vascular sympathetic activity) in CTRL animals, whereas there were no changes of these parameters in PhADX animals (Fig. 2 B, D, F). HF SBPV (representing cardiac sympathetic activity) in CTRL animals was slightly increased by stress, while no stress-induced increase was observed in PhADX animals (Fig. 2H). In Tables 1 and 2 are results of two-way repeated measures ANOVA analysis of data shown in Figures 1 and 2. Under the stress condition, total count of spontaneous baroreflex sequences (sBRS) was lower in PhADX group (CTRL $221 \pm 49$, PhADX $33 \pm 10, \mathrm{p}<0.05)$, but sBRS slope was similar in both experimental groups (CTRL $1.3 \pm 0.1 \mathrm{~ms} / \mathrm{mm} \mathrm{Hg}$, PhADX $1.8 \pm 0.2 \mathrm{~ms} / \mathrm{mm} \mathrm{Hg}$ ).

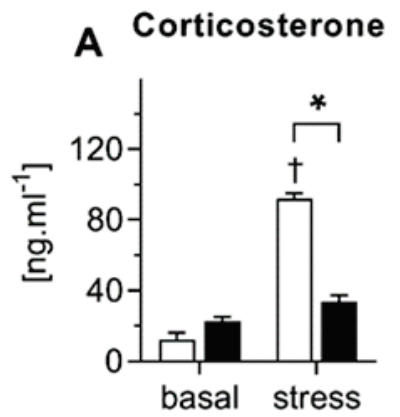

C Aldosterone
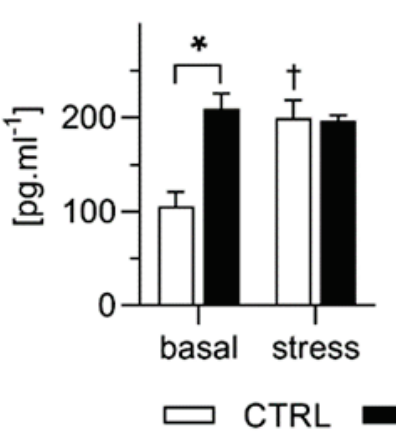

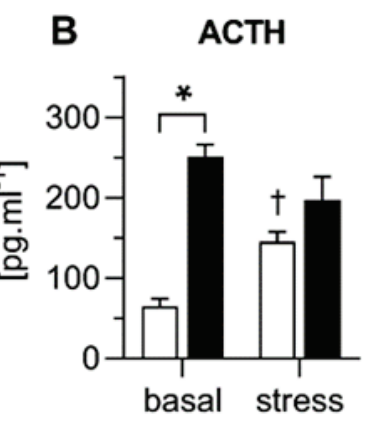

D Plasma renin

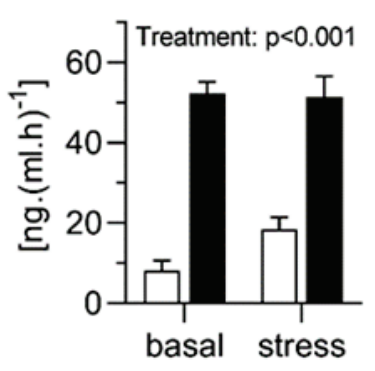

PhADX
Fig. 3. Plasma concentrations of corticosterone (A), ACTH (B), aldosterone (C) and plasma renin activity (D) in control (CTRL) or pharmacologically adrenalectomized (PhADX) rats. The values are expressed as the mean $\pm S E M, n=6$ rats for each group. The main effects of Treatment (CTRL vs. PhADX rats) and Stress (basal vs. stress) were analyzed by two-way ANOVA. Corticosterone: treatment $F_{1,20}=48.5, p<0.001$; stress $F_{1,20}=174$, $\mathrm{p}<0.001$; interaction $\mathrm{F}_{1,20}=101, \mathrm{p}<0.001 ; \mathrm{ACTH}$ : treatment $F_{1,20}=44.6, p<0.001$; stress $F_{1,20}=0.56, N S$; interaction $F_{1,20}=14.0$, $\mathrm{p}<0.01$; aldosterone: treatment $\mathrm{F}_{1,20}=11.4, \mathrm{p}<0.01$; stress $F_{1,20}=7.44, p<0.05$; interaction $F_{1,20}=12.8, p<0.01$; plasma renin activity: treatment $F_{1,20}=117, p<0.001$; stress $F_{1,20}=1.65$, NS; interaction $F_{1,20}=2.47, p=0.13$. The pairwise simple effects of significant interactions were tested by Bonferroni post hoc test: $* p<0.05$ CTRL vs. PhADX group, ${ }^{\dagger} p<0.05$ vs. basal unstressed level.

\section{Plasma hormone levels}

Basal corticosterone levels were not affected by PhADX (Fig. 3A), but basal plasma levels of ACTH were 5-fold higher in $\mathrm{PhADX}$ compared to $\mathrm{CTRL}$ group (Fig. 3B). Similarly to ACTH, 120 min after the injection of inhibitors, plasma renin activity and plasma aldosterone levels were significantly increased by PhADX (6-fold and 2-fold, respectively, Fig. 3C, D). PhADX also increased plasma levels of epinephrine (CTRL $\quad 0.9 \pm 0.2$ ng. $\mathrm{ml}^{-1}, \quad$ PhADX $\quad 1.93 \pm 0.2$ ng.ml ${ }^{-1}$, $\mathrm{p}<0.01$ ) and norepinephrine (CTRL $1.4 \pm 0.1 \mathrm{ng} . \mathrm{ml}^{-1}$, PhADX $1.7 \pm 0.1$ ng. $\left.\mathrm{ml}^{-1}, \mathrm{p}<0.05\right)$. In CTRL rats the restraint stress for $10 \mathrm{~min}$ increased plasma levels of ACTH, corticosterone and aldosterone, while in PhADX animals 10 min of stress did not affect plasma levels of either measured hormone (Fig. 3). Results of two-way ANOVA analysis for plasma levels of hormones are shown in caption of Fig. 3.

$B P$ response to administration of the graded doses of norepinephrine

Anesthetized PhADX rats exhibited lower MAP (CTRL 125 $\pm 5 \mathrm{~mm} \mathrm{Hg}$, PhADX $93 \pm 7 \mathrm{~mm} \mathrm{Hg}, \mathrm{p}<0.01$ ) but unchanged HR (CTRL 358 \pm 3 bpm, PhADX $312 \pm$ $27 \mathrm{bpm})$ as compared to CTRL animals. Ganglionic blockade by pentolinium lowered MAP (CTRL $-41 \pm 5 \mathrm{~mm} \mathrm{Hg}, \mathrm{PhADX}-30 \pm 5 \mathrm{~mm} \mathrm{Hg}$ PhADX) and HR (CTRL $-38 \pm 2 \mathrm{bpm}$, PhADX $-44 \pm 11 \mathrm{bpm}$ ) similarly in

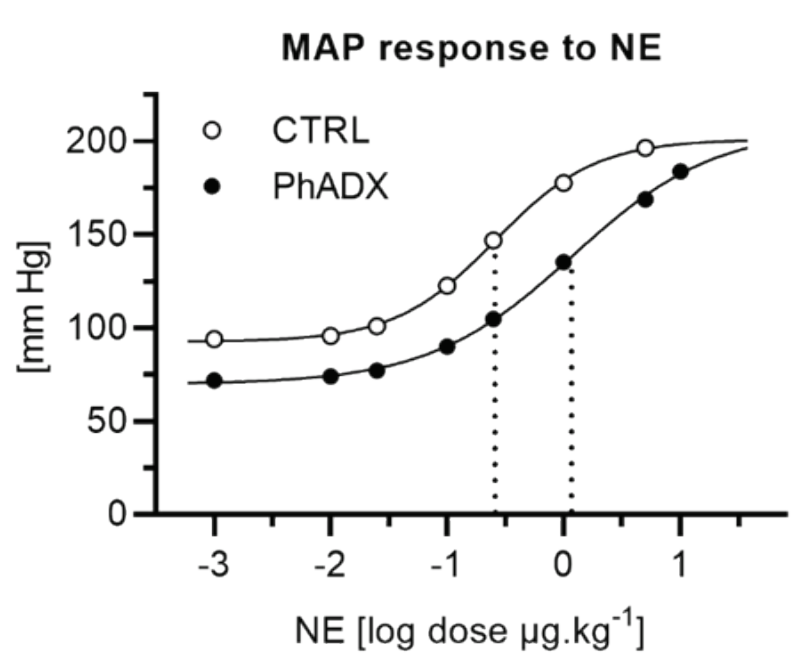

Fig. 4. Mean arterial pressure (MAP) response to the administration of graded doses of norepinephrine $(0.001-10 \mu \mathrm{g} / \mathrm{kg})$ in pentobarbital-anesthetized control (CTRL) and pharmacologically adrenalectomized (PhADX) rats. The values are expressed as the mean \pm SEM, $n=5-6$ rats for each group. Data were fitted with sigmoidal logistic curve and halfmaximal effective dose (ED50) of particular group is indicated by dotted line. 
both experimental groups. The sensitivity to NE (Fig. 4), analyzed as half-maximal effective dose (ED50), was decreased in PhADX $(1.19 \pm 0.21 \mu \mathrm{g} / \mathrm{kg})$ compared to CTRL rats $(0.26 \pm 0.03 \mu \mathrm{g} / \mathrm{kg}, \mathrm{p}<0.05)$.

\section{Discussion}

Acute pharmacological adrenalectomy (PhADX) attenuated stress-induced increase of BP, HR and core body temperature, and prevented stress-induced increase of total SBPV and its individual frequency components LF SBPV as a marker of vascular sympathetic activity and HF SBPV as a marker of cardiac sympathetic activity. Sensitivity of cardiovascular system to exogenous norepinephrine administration was attenuated in PhADX rats. Furthermore, acute PhADX increased basal plasma levels of ACTH, aldosterone and plasma renin activity in unstressed animals, but PhADX prevented stress-induced increase of these hormones.

Plotsky and Sawchenko (1987) suggested that PhADX might be a valid alternative to surgical adrenalectomy since PhADX leads to a suppression of circulating levels of corticosterone in rat. In our experiments, acute PhADX prevented stress-induced increase of plasma corticosterone but it did not lower basal plasma levels of corticosterone under the unstressed conditions $120 \mathrm{~min}$ after the injection of inhibitors. This was likely to be due to the interaction between direct inhibition of corticosterone synthesis and the concomitant stimulation of the adrenal cortex by high ACTH levels (Plotsky et al. 1986, Rotllant et al. 2002). In fact, we observed a several fold increase of basal plasma ACTH levels in $\mathrm{PhADX}$ rats. This might result from the absence of feedback regulation. The exposure to restraint did not further increase plasma ACTH levels in PhADX animals, which might be due to a ceiling effect. Basal plasma aldosterone levels were also increased in PhADX animals and they were not further enhanced by stress. Aldosterone secretion is triggered by increased plasma angiotensin II, ACTH and/or potassium levels (Hattangady et al. 2012). In PhADX rats, we observed not only elevated ACTH levels but also substantially enhanced plasma renin activity. The most likely mechanism of PhADX-induced renin secretion seems to be increased sympathetic nerve activity (Harrison-Bernard 2009) which can be indicated by increased plasma catecholamine levels in PhADX animals. This is in a good agreement with the observation of Brown and Fisher (1986) who demonstrated that adrenalectomy elevated basal plasma NE levels and augmented stress-induced rise of plasma NE concentrations. Accordingly, pretreatment with exogenous GCs (dexamethasone or corticosterone) suppressed stress-induced elevations of plasma NE and epinephrine levels (Brown and Fisher 1986). Furthermore, ACTH has a direct effect on the juxtaglomerular cells causing a rise in plasma renin activity (Hauger-Klevene et al. 1969). Taken together, the suppression of corticosterone synthesis by PhADX increased basal plasma levels of ACTH, aldosterone and plasma renin activity in unstressed animals but there was no further increase of these hormones following stressor exposure.

PhADX decreased BP and HR in pentobarbitalanesthetized rats, but did not alter BP in freely moving conscious rats. Nevertheless, BP lowering effect of acute PhADX might be masked by tachycardia observed in conscious animals. We found a decrease in the total number of baroreflex events after PhADX, which might indicate altered function of autonomic nervous system. Similarly, surgical adrenalectomy attenuated baroreflex responsiveness and corticosterone replacement was able to restore this effect (Darlington et al. 1989). Stressinduced increases of BP and HR during initial phase of restraint, mediated by increased sympathetic nerve activity, were attenuated by PhADX. All above mentioned relatively rapid effects of acute PhADX (within minutes) are incompatible with a "classical" genomic regulation (via transcription) and invoke noncanonical mode of GCs action (Tasker et al. 2006, de Kloet et al. 2008). Membrane forms of mineralocorticoid and glucocorticoid receptors regulate ion channels that induce rapid changes in synaptic transmission and neuron excitability (Prager and Johnson 2009). In our experiments, PhADX prevented stressinduced increase of LF and HF SBPV (representing vascular and cardiac sympathetic activity, respectively) similarly to the effects of chronic sympathectomy described recently (Vavř́nová et al. 2019). However, the particular components of SBPV are indirect markers of sympathetic nerve activity depending on a proper function of cardiovascular effectors. PhADX did not abolish BP and HR lowering effects of ganglionic blocker pentolinium in pentobarbital-anesthetized rats, which indicates preserved sympathetic function in PhADX rats. Our observation of elevated catecholamines concentrations in PhADX rats suggests that circulating catecholamines are not always decisive for cardiovascular response to stressor. It was documented that GCs might 
prolong catecholamine stability in the sympathetic synapse by inhibiting catecholamine reuptake, increase the efficacy of catecholamines at adrenergic receptors and influence receptor-G protein coupling and catecholamineinduced cAMP synthesis (Dailey and Westfall 1978, Haigh and Jones 1990, Sapolsky et al. 2000). Furthermore, corticosteroids act directly on vascular smooth muscle cells and play an important role in the control of vascular smooth muscle tone by their permissive effects, potentiating responses to vasoconstrictors (Ullian 1999, Yang and Zhang 2004). We documented a decreased sensitivity of cardiovascular system to catecholamines in $\mathrm{PhADX}$ rats by the rightward shift of NE dose-response for BP. Similarly, surgical adrenalectomy also reduced systemic pressor responsiveness to norepinephrine or phenylephrine, while dexamethasone or corticosterone administration was able to restore BP sensitivity to vasoconstrictors (Yagil and Krakoff 1988, Darlington et al. 1989). Therefore, the increased catecholamine concentrations after adrenalectomy should be appropriately considered as a partial compensation for the absence of these GCs modulatory effects on cardiovascular system (Sapolsky et al. 2000).

PhADX not only attenuated stress-induced increase of body temperature but it also decreased basal body temperature. It was demonstrated that sympathetic activation leads to a stimulation of $\beta$-adrenergic receptors in brown adipose tissue resulting in heat production (Morrison et al. 2008). Moreover, Ootsuka et al. (2008) showed a considerable rise in temperature of the interscapular brown adipose tissue during restraint stress, which might be inhibited by chemical sympathectomy (Shibata and Nagasaka 1984). The other factors contributing to stress-induced hyperthermic response are elevation of HR, metabolic heat production and reduction in heat lost due to sympathetic peripheral vasoconstriction (Nagasaka et al. 1979, Aydin et al. 2011). It was demonstrated that stress-induced hyperthermia is attenuated by surgical adrenalectomy (Gao et al. 2003) and can be restored by the administration of corticosterone (van der Busse et al. 2002). Thus, the crucial role of GCs in the regulation of body temperature could be mediated by their permissive effects on sympathetically controlled tissues participating in thermoregulation.

Limitations: The current study has several limitations that need to be addressed. First, the acute but not chronic pharmacological inhibition of corticosterone synthesis was performed. Our findings thus can not be simply extrapolated to the experiments concerning surgical adrenalectomy which describe long-term effects of glucocorticoid deficiency for several days. Second, stress-induced plasma levels of hormones were measured only during initial phase of restraint. A detailed timecourse of changes in plasma levels of hormones during the exposure to stressor and during the recovery phase should be determined. Third, it was demonstrated that except for inhibition of $11 \beta$-hydroxylase, metyrapone could also inhibit 11 $\beta$-hydroxysteroid dehydrogenase type 1 (Sampath-Kumar et al. 1997). Therefore our treatment attenuated not only de novo synthesis of corticosterone, but could also inhibit the regeneration of biologically active corticosterone from inactive 11-dehydrocorticosterone in extra-adrenal tissue. Both abovementioned effects contribute to the reduced availability of the active form of glucocorticoid (corticosterone).

\section{Conclusions}

Our results indicate an important permissive and/or stimulating role of GCs in the maintenance of sympathetically mediated peripheral vascular resistance, thermoregulation and especially in the adequate response of cardiovascular system to stressor exposure. The increased plasma catecholamines and plasma renin activity in PhADX animals might be related to compensatory changes aiming to maintain the homeostasis in the absence of GCs rather than to suppressive effects of GCs in particular processes of sympathetic transmission.

\section{Conflict of Interest}

There is no conflict of interest.

\section{Acknowledgements}

This study was supported by grants from the Czech Science Foundation (GACR 16-10349Y) and partially by Joint Project of the Czech Science Foundation and MOST Taiwan (GACR 19-08260J). 


\section{References}

AYDIN C, GRACE CE, GORDON CJ: Effect of physical restraint on the limits of thermoregulation in telemetered rats. Exp Physiol 96: 1218-1227, 2011. https://doi.org/10.1113/expphysiol.2011.060301

BEHULIAK M, PINTÉROVÁ M, BENCZE M, PETROVÁ M, LÍŠKOVÁ S, KAREN P, KUNEŠ J, VANĚČKOVÁ I, ZICHA J: $\mathrm{Ca} 2+$ sensitization and $\mathrm{Ca} 2+$ entry in the control of blood pressure and adrenergic vasoconstriction in conscious Wistar-Kyoto and spontaneously hypertensive rats. J Hypertens 31: 2025-2035, 2013. https://doi.org/10.1097/hjh.0b013e328362adb3

BEHULIAK M, BENCZE M, POLGÁROVÁ K, KUNEŠ J, VANĚČKOVÁ I, ZICHA J: Hemodynamic response to gabapentin in conscious spontaneously hypertensive rats. Hypertension 72: 676-685, 2018. https://doi.org/10.1161/hypertensionaha.118.09909

BENCZE M, BEHULIAK M, ZICHA J: The impact of four different classes of anesthetics on the mechanisms of blood pressure regulation in normotensive and spontaneously hypertensive rats. Physiol Res 62: 471-478, 2013.

BERTINIERI G, DI RIENZO M, CAVALLAZZI A, FERRARI AU, PEDOTTI A, MANCIA G: A new approach to analysis of the arterial baroreflex. J Hypertens 3 (Suppl): S79-S81, 1985.

BROWN MR, FISHER LA: Glucocorticoid suppression of the sympathetic nervous system and adrenal medulla. Life Sci 39: 1003-1012, 1986. https://doi.org/10.1016/0024-3205(86)90289-4

DAILEY JW, WESTFALL TC: Effects of adrenalectomy and adrenal steroids on norepinephrine synthesis and monamine oxidase activity. Eur J Pharmacol 48: 383-391, 1978. https://doi.org/10.1016/0014-2999(78)90165-6

DARLINGTON DN, KASHIP K, KEIL LC, DALLMAN MF: Vascular responsiveness in adrenalectomized rats with corticosterone replacement. Am J Physiol 256: H1274-H1281, 1989. https://doi.org/10.1152/ajpheart.1989.256.5.h1274

DE KLOET ER, KARST H, JOËLS M: Corticosteroid hormones in the central stress response: quick-and-slow. Front Neuroendocrinol 29: 268-272, 2008. https://doi.org/10.1016/j.yfrne.2007.10.002

Dos REIS DG, FORTALEZA EA, TAVARES RF, CORREAA FM: Role of the autonomic nervous system and baroreflex in stress-evoked cardiovascular responses in rats. Stress 17: 362-372, 2014. https://doi.org/10.3109/10253890.2014.930429

FRITZ I, LEVINE R: Action of adrenal cortical steroids and nor-epinephrine on vascular responses of stress in adrenalectomized rats. Am J Physiol 165: 456-465, 1951. https://doi.org/10.1152/ajplegacy.1951.165.2.456

GAO B, KIKUCHI-UTSUMI K, OHINATA H, HASHIMOTO M, KUROSHIMA A: Repeated immobilization stress increases uncoupling protein 1 expression and activity in Wistar rats. Jpn J Physiol 53: 205-213, 2003. https://doi.org/10.2170/ijphysiol.53.205

GOLDSTEIN DS: Adrenal responses to stress. Cell Mol Neurobiol 30: 1433-1440, 2010. https://doi.org/10.1007/s10571-010-9606-9

HAIGH RM, JONES CT: Effect of glucocorticoids on alpha 1-adrenergic receptor binding in rat vascular smooth muscle. J Mol Endocrinol 5: 41-48, 1990. https://doi.org/10.1677/jme.0.0050041

HARRISON-BERNARD LM: The renal renin-angiotensin system. Adv Physiol Educ 33: 270-274, 2009. https://doi.org/10.1152/advan.00049.2009

HATTANGADY NG, OLALA LO, BOLLAG WB, RAINEY WE: Acute and chronic regulation of aldosterone production. Mol Cell Endocrinol 350: 151-162, 2012. https://doi.org/10.1016/j.mce.2011.07.034

HAUGER-KLEVENE JH, BROWN H, FLEISCHER N: ACTH stimulation and glucocorticoid inhibition of renin release in the rat. Proc Soc Exp Biol Med 131: 539-542, 1969. https://doi.org/10.3181/00379727-131-33920

KOOLHAAS JM, BARTOLOMUCCI A, BUWALDA B, DE BOER SF, FLÜGGE G, KORTE SM, MEERLO P, MURISON R, OLIVIER B, PALANZA P, RICHTER-LEVIN G, SGOIFO A, STEIMER T, STIEDL O, VAN DIJK G, WÖHR M, FUCHS E: Stress revisited: a critical evaluation of the stress concept. Neurosci Biobehav Rev 35: 1291-1301, 2011. https://doi.org/10.1016/j.neubiorev.2011.02.003

KVETŇANSKÝ R, FUKUHARA K, PACÁK K, CIZZA G, GOLDSTEIN DS, KOPIN IJ: Endogenous glucocorticoids restrain catecholamine synthesis and release at rest and during immobilization stress in rats. Endocrinology 133: 1411-1419, 1993. https://doi.org/10.1210/endo.133.3.8396019 
MCDOUGALL SJ, PAULL JR, WIDDOP RE, LAWRENCE AJ: Restraint stress: differential cardiovascular responses in Wistar-Kyoto and spontaneously hypertensive rats. Hypertension 35: 126-129, 2000. https://doi.org/10.1161/01.hyp.35.1.126

MCEWEN BS: Protective and damaging effects of stress mediators. N Engl J Med 338: 171-179, 1998. https://doi.org/10.1056/NEJM199801153380307

MORRISON SF, NAKAMURA K, MADDEN CJ: Central control of thermogenesis in mammals. Exp Physiol 93: 773-797, 2008. https://doi.org/10.1113/expphysiol.2007.041848

NAGASAKA T, HIRATA K, SUGANO Y, SHIBATA H: Heat balance during physical restraint in rats. Jpn J Physiol 29: 383-392, 1979. https://doi.org/10.2170/jiphysiol.29.383

OOTSUKA Y, BLESSING WW, NALIVAIKO E: Selective blockade of 5-HT2A receptors attenuates the increased temperature response in brown adipose tissue to restraint stress in rats. Stress 11: 125-133, 2008. https://doi.org/10.1080/10253890701638303

PLOTSKY PM, OTTO S, SAPOLSKY RM: Inhibition of immunoreactive corticotropin-releasing factor secretion into the hypophysial-portal circulation by delayed glucocorticoid feedback. Endocrinology 119: 1126-1130, 1986. https://doi.org/10.1210/endo-119-3-1126

PLOTSKY PM, SAWCHENKO PE: Hypophysial-portal plasma levels, median eminence content, and immunohistochemical staining of corticotropin-releasing factor, arginine vasopressin, and oxytocin after pharmacological adrenalectomy. Endocrinology 120: 1361-1369, 1987. https://doi.org/10.1210/endo-120-41361

PRAGER EM, JOHNSON LR: Stress at the synapse: signal transduction mechanisms of adrenal steroids at neuronal membranes. Sci Signal 2: re5, 2009. https://doi.org/10.1126/scisignal.286re5

ROTLLANT D, ONS S, CARRASCO J, ARMARIO A: Evidence that metyrapone can act as a stressor: effect on pituitary-adrenal hormones, plasma glucose and brain c-fos induction. Eur J Neurosci 16: 693-700, 2002. https://doi.org/10.1046/j.1460-9568.2002.02120.x

SAMPATH-KUMAR R, YU M, KHALIL MW, YANG K: Metyrapone is a competitive inhibitor of 11 betahydroxysteroid dehydrogenase type 1 reductase. J Steroid Biochem Mol Biol 62: 195-199, 1997. https://doi.org/10.1016/s0960-0760(97)00027-7

SANTEN RJ, MISBIN RI: Aminoglutethimide: review of pharmacology and clinical use. Pharmacotherapy 1: 95-120, 1981. https://doi.org/10.1002/j.1875-9114.1981.tb03557.x

SAPOLSKY RM, ROMERO LM, MUNCK AU: How do glucocorticoids influence stress responses? Integrating permissive, suppressive, stimulatory, and preparative actions. Endocr Rev 21: 55-89, 2000. https://doi.org/10.1210/er.21.1.55

SHIBATA H, NAGASAKA T: Role of sympathetic nervous system in immobilization- and cold-induced brown adipose tissue thermogenesis in rats. Jpn J Physiol 34: 103-111, 1984. https://doi.org/10.2170/jiphysiol.34.103

STAUSS HM: Identification of blood pressure control mechanisms by power spectral analysis. Clin Exp Pharmacol Physiol 34: 362-368, 2007. https://doi.org/10.1111/j.1440-1681.2007.04588.x

TASKER JG, DI S, MALCHER-LOPES R: Minireview: rapid glucocorticoid signaling via membrane-associated receptors. Endocrinology 147: 5549-5556, 2006. https://doi.org/10.1210/en.2006-0981

ULLIAN ME: The role of corticosteriods in the regulation of vascular tone. Cardiovasc Res 41: 55-64, 1999.

VAN DEN BUUSE M, VAN ACKER SA, FLUTTERT MF, DE KLOET ER: Involvement of corticosterone in cardiovascular responses to an open-field novelty stressor in freely moving rats. Physiol Behav 75: 207-215, 2002. https://doi.org/10.1016/s0031-9384(01)00642-4

VAVŘÍNOVÁ A, BEHULIAK M, BENCZE M, VODIČKA M, ERGANG P, VANĚČKOVÁ I, ZICHA J: Sympathectomy-induced blood pressure reduction in adult normotensive and hypertensive rats is counteracted by enhanced cardiovascular sensitivity to vasoconstrictors. Hypertens Res 42: 1872-1882, 2019. https://doi.org/10.1038/s41440-019-0319-2

WU XY, HU YT, GUO L, LU J, ZHU QB, YU E, WU JL, SHI LG, HUANG ML, BAO AM: Effect of pentobarbital and isoflurane on acute stress response in rat. Physiol Behav 145: 118-121, 2015. https://doi.org/10.1016/j.physbeh.2015.04.003 
YAGIL Y, KRAKOFF LR: The differential effect of aldosterone and dexamethasone on pressor responses in adrenalectomized rats. Hypertension 11: 174-178, 1988. https://doi.org/10.1161/01.hyp.11.2.174

YANG S, ZHANG L: Glucocorticoids and vascular reactivity. Curr Vasc Pharmacol 2: 1-12, 2004. https://doi.org/10.2174/1570161043476483 